\title{
An Experimental, Non-Uremic Rabbit Model of Peritoneal Dialysis
}

\author{
S. ZUNIC-BOZINOVSKI ${ }^{1}$, Z. LAUSEVIC ${ }^{2}$, S. KRSTIC ${ }^{2}$, N. JOVANOVIC ${ }^{3}$, \\ J. TRBOJEVIC-STANKOVIC ${ }^{4}$, B. STOJIMIROVIC ${ }^{3}$
}

${ }^{1}$ Institute of Pathophysiology, School of Medicine, University of Belgrade, ${ }^{2}$ Institute for Digestive Diseases, Clinical Center of Serbia, ${ }^{3}$ Clinic of Nephrology, Clinical Center of Serbia, ${ }^{4}$ Center for Urology, Department of Hemodialysis, Clinical-Hospital Center „Dr Dragisa Misovic”, Belgrade, Serbia

Received September 1, 2006

Accepted October 5, 2006

On-line available November 6, 2006

\begin{abstract}
Summary
Peritoneal dialysis (PD) is a well established method of depuration in uremic patients. Standard dialysis solutions currently in use are not biocompatible with the peritoneal membrane. Studying effects of dialysate on peritoneal membrane in humans is still a challenge. There is no consensus on the ideal experimental model so far. We, therefore, wanted to develop a new experimental non-uremic rabbit model of peritoneal dialysis, which would be practical, easy to conduct, not too costly, and convenient to investigate the long-term effect of dialysis fluids. The study was done on 17 healthy Chinchilla male and female rabbits, anesthetized with Thiopental in a dose of $0.5 \mathrm{mg} / \mathrm{kg}$ body mass. A catheter, specially made from Tro-soluset (Troge Medical GMBH, Hamburg, Germany) infusion system, was then surgically inserted and tunneled from animals' abdomen to their neck. The planned experimental procedure was 4 weeks of peritoneal dialysate instillation. The presented non-uremic rabbit model of peritoneal dialysis is relatively inexpensive, does not require sophisticated technology and was well tolerated by the animals. Complications such as peritonitis, dialysis fluid leakage, constipation and catheter obstruction were negligible. This model is reproducible and can be used to analyze the effects of different dialysis solutions on the rabbit peritoneal membrane.
\end{abstract}

\section{Key words}

Peritoneal dialysis • Experimental model $\bullet$ Non-uremic rabbit

\section{Corresponding author}

S. Zunic-Bozinovski, Boce i Jakse 26, 11077 New Belgrade, Serbia. E-mail: nzunic@ptt.yu

\section{Introduction}

Peritoneal dialysis (PD) is a well-established method of depuration in the end-stage renal disease patients. The PD system consists of three main components: peritoneal microcirculation, peritoneal membrane and the dialysate compartment. The peritoneal filtration membrane is composed of peritoneal mesothelial cells, mesothelial basement membrane, connective tissue, blood vessels basement membrane and endothelium. This living structure is more a functional barrier than strictly an anatomical formation.

Standard dialysis solutions currently in use are not biocompatible with the peritoneal membrane. They contain glucose in high, non-physiological concentrations, acting as an osmotic substance. Furthermore, the dialysate contains lactates which maintain its low $\mathrm{pH}$, thus contributing to its negative effects on the peritoneal tissue. During sterilization and preservation of the solute, glucose degradation products and advanced glucose degradation products are formed, which adversely affect the peritoneal structures. The high glucose concentration causes non-enzymatic glycosylation of tissue proteins. This may explain the resemblance of morphological alterations in peritoneal microcirculation during long-term dialysis to those found in blood vessels of diabetic patients: loss of the mesothelial layer, thickening of submesothelium due to increased deposition of collagen and hyaluron in interstitium, interstitial fibrosis, thickening of mesothelial basement membrane and endothelial basement membrane 
of small peritoneal blood vessels accompanied by neoangiogenesis (Stojimirovic et al. 2001). Histolo-gical changes correlate with dialysis duration and frequency of the use of dialysate with high glucose concentration. Structural changes affect the quality of dialysis, as they increase the velocity of low molecular mass solute transport, increase peritoneal microvascular surface and decrease ultrafiltration rates.

Studying the effects of dialysate on peritoneal membrane in humans is still a challenge due to ethical and technical limitations, as tissue samples can be obtained solely when placing or removing the peritoneal catheter. Therefore, various experimental models have been developed in order to investigate the impact of dialysis solutions on peritoneal tissue (Ter Wee et al. 2003). There is, however, still no consensus on the ideal experimental model (Topley 2005, Mortier et al. 2005).

We therefore aimed to develop a new, experimental, non-uremic rabbit model of peritoneal dialysis, which would be practical, easy to perform, inexpensive, and convenient to study the long-term effect of dialysis fluids.

\section{Methods}

Animals

The study was performed on 17 healthy Chinchilla male and female rabbits, weighing $2739 \pm 388$ $g$ at the beginning of the experiment.

The rabbits were kept in individual cages and received standard rabbit pellets (Veterinary Institute, Subotica, Serbia) and water ad libitum. All rabbits were allowed to adapt to the new living conditions for at least five days prior to catheter insertion. Eleven rabbits (6 male and 5 female) completed the entire planned experimental procedure, i.e. 4 weeks of peritoneal dialysate instillation. During the study period of five weeks (one week for recovery following catheter placement, and four weeks of dialysis) a diary of animal behavior was kept. It included the following data: body mass, body temperature, food intake, diuresis, defecation, antibiotics administration, other therapy and interventions if necessary (wound toilette, catheter suturing etc.).

\section{Sample collecting}

Peritoneal tissue is extremely fragile and susceptible to mechanical irritation and environmental factors. Collecting tissue samples was therefore perfomed strictly respecting the guidelines from literature (Di Paolo et al. 1996, Gotloib and Shoshtak 2000, Williams et al. 2002). Ellipsoid tissue samples, $18 \mathrm{~mm} \times 3 \mathrm{~mm}$, of parietal peritoneum were taken immediately after opening the abdomen (Dobbie 1993). The tissue was fixed straight away for $24 \mathrm{~h}$ in $10 \%$ formaldehyde with $0.1 \mathrm{M}$ Sorensen's phosphate buffer $\mathrm{pH} 7.4$, dehydrated in $96 \%$ ethanol, then routinely processed for embedding in paraplast, and stained with hematoxylin-eosin and toluidin-blue to be analyzed by light microscopy (Opton Photomikroskop III).

For transmission electron microscopy (TEM) tissue samples were fixed for $24 \mathrm{~h}$ in $4 \%$ glutaraldehyde with $1 \%$ tanine acid to ensure better fixation of membrane structures. Without tanine acid fixation lasted from $24 \mathrm{hs}$ to several days. Fixatives were diluted in cacodylate or Sorensen's phosphate buffer 0.1 M, pH 7.4. The tissue was then rinsed three times for $10 \mathrm{~min}$ with the same buffer, and then three times for $10 \mathrm{~min}$ in cacodylate buffer. Samples were postfixed with $1 \%$ osmium tetroxide in $0.1 \mathrm{M}$ cacodylate buffer, $\mathrm{pH} 7.4$ and left overnight in $4 \%$ uranyl acetate. They were then dehydrated in ethanol and propylene-oxide and embedded in Epon. Fine sections were contrasted with uranyl acetate and lead-citrate (Hayat 1986) and analyzed with a transmission electron microscope (Philips M208S).

\section{Anesthesia procedure}

Animals were anesthetized according to an existing protocol which was adapted during the study. For catheter implantation and removal rabbits were anesthetized intravenously with Thiopental BP $1 \mathrm{G}$ (Rotexmedica, Trittau, Germany) $1 \mathrm{ng} / \mathrm{kg}$ body mass via an ear vein. After losing two animals with this protocol, other rabbits were anesthetized with the same anesthetic (Thiopental injection BP 1G), via the same route, but the dose was halved to $0.5 \mathrm{mg} / \mathrm{kg}$ body mass. This dose of anesthetic was sufficient for adequate catheter implantation or removal and showed no adverse effects on the animals.

\section{Surgical procedure}

Catheter placement was a modified version of the procedure described by Zweers et al. (1999). At the beginning of our study we used double-lumen central venous catheter (Arrow International Inc. USA Product No. CV-17702-E) as a peritoneal catheter. Implantation of this catheter was performed as described in the following text. 


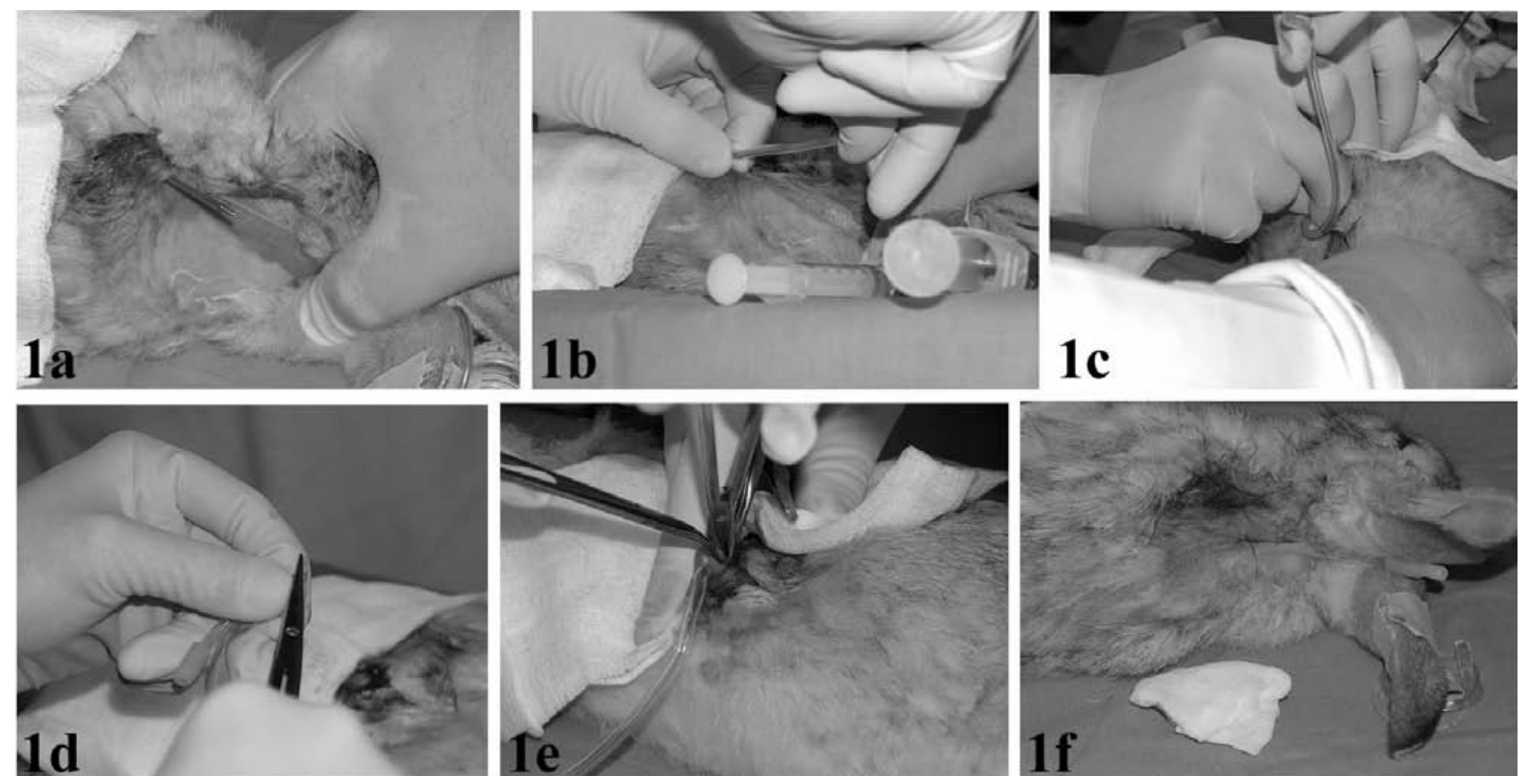

Fig. 1. Surgical procedure of catheter placement (for detailed explanation see the text).

When anesthetized, the animals were shaved on the back of the neck between the ears and scapulae, as well as below the left costal arch (upper left hemiabdomen). The surgical field was prepared in a standard way. Then, a longitudal incision, 3 to $4 \mathrm{~cm}$ long, was made with a scalpel, starting $2-3 \mathrm{~cm}$ distally from the left costal arch edge, $4-5 \mathrm{~cm}$ from median abdominal line and in parallel to it.

After the skin was cut, subcutaneous space was entered either sharply or partly bluntly, and a tunnel was made from the abdomen to the neck area, with a thoracic drain No. 16 mandren (Figure 1a). The catheter was made to exit in the dorsal part of the neck, between the ears. The double-lumen central venous catheter was then pulled over the mandren and carefully pulled back, through the tunnel, into the abdominal region. Abdominal muscles were then sharply or bluntly moved apart to access the peritoneum. Immediately after opening the peritoneal cavity, biopsies of peritoneal tissue were taken from diagonal edges and the catheter was placed on the floor of the peritoneal cavity.

Peritoneum was sutured with a continuous suture using Vicril 4-0. Part of the catheter was fixed to it. Muscles were sutured with chromium Cutgut 3-0, and fascias with ongoing suture using Vicril (Dexon) 3-0. The skin was closed with single sutures. The catheter was fixed in the tissue at its entrance and exit sites. A sterile gauze was placed at both sites and fixed with a bandage wrapped around the body.
The double-lumen central venous catheter (used as the peritoneal catheter) was placed in the described manner in four animals. In the first few postoperative days, however, the rabbits bit off the external catheter branches and even pulled out the whole catheters, even though they were fixed at both ends. Due to their length, branches of the catheter stretched over animals' ears, irritated them and were easily accessible. These catheters could not be shortened as they had an original extension for attaching the infusion systems on their exit end.

This procedure, therefore, had to be modified. During the further course of our study we used a part of the infusion system Tro-soluset (Troge Medical GMBH, Hamburg, Germany), initially shortened to $45 \mathrm{~cm}$, as a dialysis catheter. Anesthesia, shaving, operative field preparation, cutaneous incision and tunneling were all performed as previously described. The infusion catheter, $45 \mathrm{~cm}$ long, was pulled over a mandren (Fig. 1b) and led through the preformed tunnel (Fig. 1c). Although the catheter was made of very soft plastic, the intraperitoneal part was sharply cut and we protected the apical part of the catheter with $1 \mathrm{~cm}$ of soft rubber from an infusion set. The rubber was pulled over the catheter apex so that it did not make any contact with the peritoneal cavity and its organs. Then, four holes (2-3 $\mathrm{mm}$ in diameter each) were made with surgical scissors at the end part of the catheter, near the rubber cap (Fig. 1d). The peritoneum was then accessed as previously described. The catheter (shortened and adjusted to the animal's size) was placed on the floor 
of peritoneal cavity (Fig. 1e). The exit site of the catheter was at the back of the neck, between the ears (Fig. 1f). The wounds were then closed as previously described.

For catheter removal a new incision, $2-3 \mathrm{~cm}$ long, was made in front of the previous one. We opted for this approach because of the existing scar and to avoid possible damage to the peritoneum when collecting tissue samples. The same access to the peritoneum was made as the one previously described. Two tissue samples, one for light and one for electron microscopy, were taken. The catheter was then identified. In four animals it had first to be carefully freed from the omentum wrapped around its tip. The rubber apical part of the catheter was excised and the catheter was pulled out through the tunnel at its exit site on the dorsal part of the animal's neck. The abdominal wound was then closed as previously described.

\section{Infection prevention}

Infection was prevented with daily injections of cefuroxime $\left(\right.$ Nilacef $^{\circledR}$, Hemofarm and GlaxoSmithKline, England). Three days prior to catheter implantation and three days following catheter removal the antibiotic was given intramusculary twice a day, in a daily dose of $150 \mathrm{mg}$. When peritoneal dialysate instillations were started, cefuroxime was administered intraperitoneally, through the catheter, once a day, in a daily dose of $75 \mathrm{mg}$. In the case that infection was suspected, gentamicin (Gentamicin $^{\circledR}$, Zdravlje, Leskovac, Serbia) was added intramusculary, in a daily dose of $2 \mathrm{mg}$.

\section{Dialysis procedure}

We used dialysis solution (Dianeal PD4 Glucose, Baxter Vertriebs GmbH, Wien, Austria) with $3.86 \% \mathrm{w} / \mathrm{v}$ glucose concentration preheated at $37{ }^{\circ} \mathrm{C}$. Dialysis solution was first instilled on the seventh day following catheter placement. Instillations were then continued daily for the total of 28 days. The full instilled dose of dialysis solution was $40 \mathrm{ml} / \mathrm{kg}$ of body mass. In order to avoid respiratory problems caused by introduction of large amounts of fluid, observed at the beginning of instillation, animals were first administered $60 \mathrm{ml}$ of the dialysate. This quantity was then increased by $10 \mathrm{ml}$ each following day until it reached $40 \mathrm{ml} / \mathrm{kg}$.

Daily heparinization was performed in order to prevent cathether clothing. After insertion, the catheter was heparinized with daily injections of 10 IU heparin sodium (Heparin $^{\circledR}$, Galenika a.d, Beograd, Serbia).

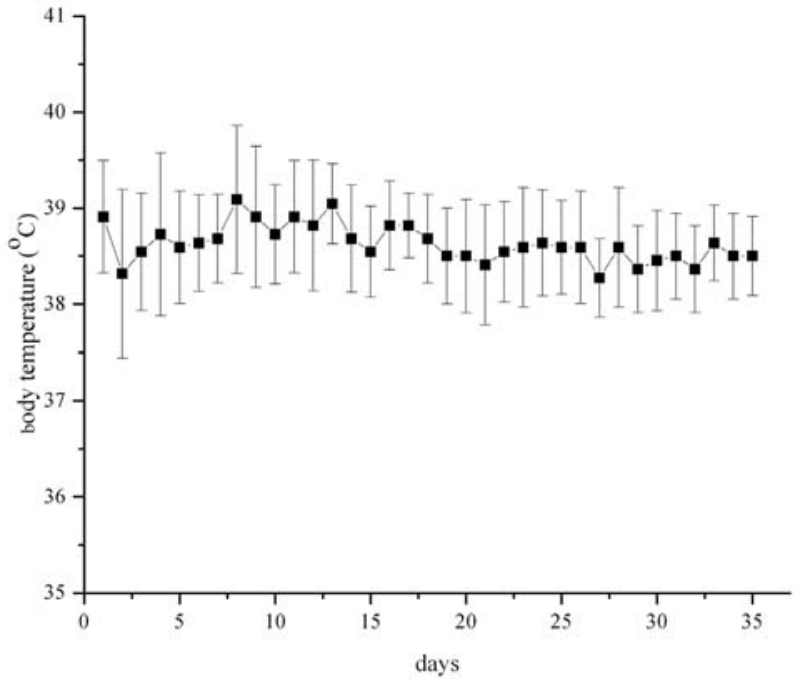

Fig. 2. The body temperature of rabbits during the study period (mean value \pm S.D).

\section{Statistical analysis}

Statistical analysis of our data was made in Origin 7.0 and Microsoft Office Excel 2003. Results were presented as mean \pm S.D.

\section{Results}

Eleven of the 17 rabbits enrolled in the study concluded the 5-week follow up, namely one week for recovery following the catheter placement and 4 weeks of daily dialysate instillation. Four rabbits were excluded from the study due to catheter loss (three of them had a double-lumen central venous catheter and one had a new, improvized catheter inserted). One rabbit died from anesthesia during peritoneal catheter implantation and one rabbit died one day following the catheter implantation. Thus $64.5 \%$ of animals concluded the 5 -week follow up, with a $89 \%$ survival rate.

The reduced dose of anesthetic, as described previously, was sufficient for adequate catheter implantation or removal and showed no adverse effects on the animals. The rabbits made complete recovery immediately after surgery.

The instillation of a full dialysate dose at the beginning of the follow up resulted in a transient episode of dyspnea in the first rabbit treated. Dyspnea spontaneously resolved in a couple hours. This problem was exceeded by starting the instillation with $60 \mathrm{ml}$ of dialysate on the first day of treatment, then increasing the amount of dialysate by $10 \mathrm{ml}$ per day until reaching the full dose. The rabbits were instilled with full dialysate 


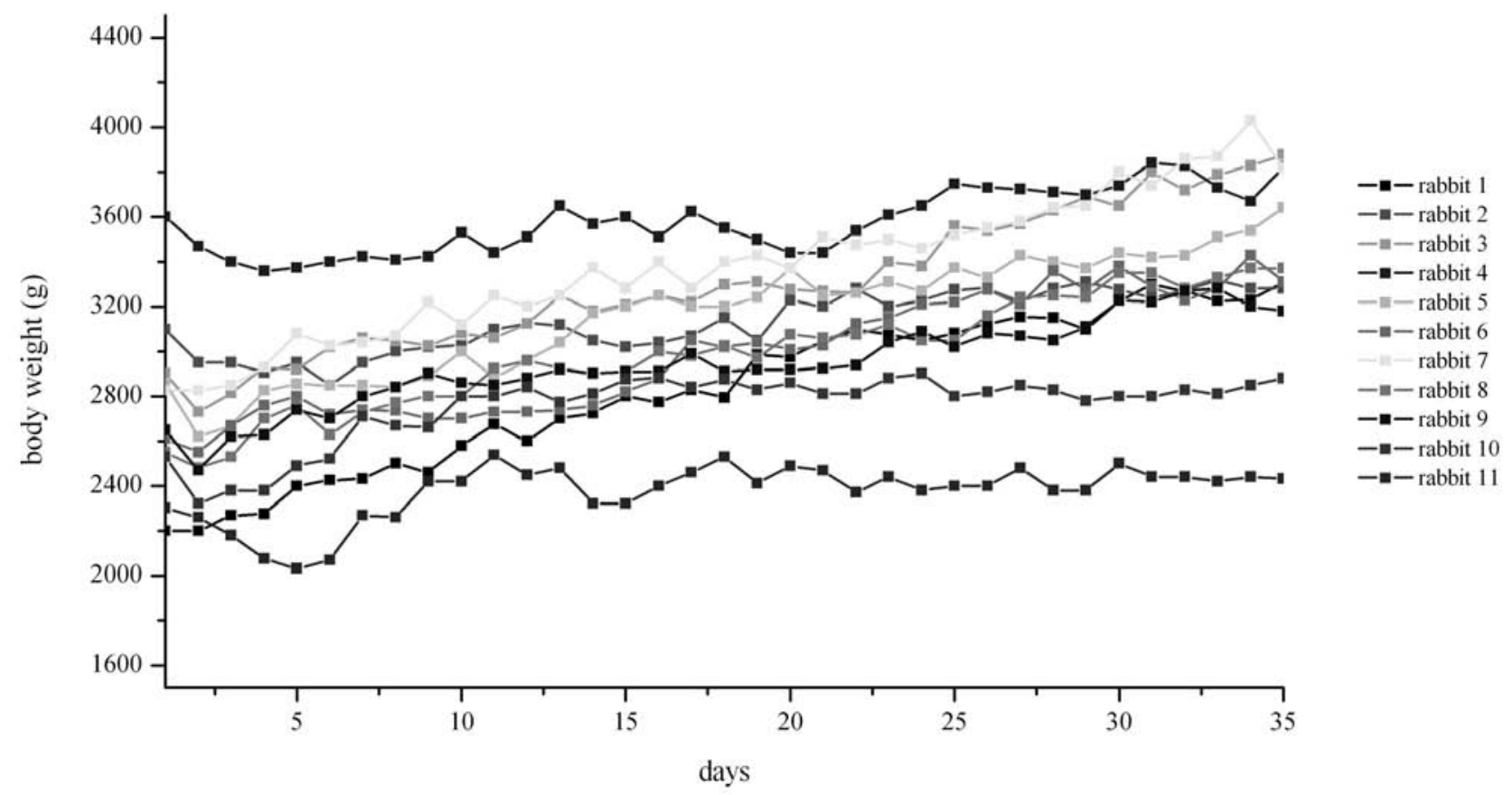

Fig. 3. Rabbits body weight during the study period. No wound infection was noted during the follow up period. No catheter obstruction was recorded during the follow up period.

dose over 5 to 7 minutes with excellent tolerance.

During the follow up, the rabbits had mostly normal body temperature (Fig. 2) and gained body weight (Fig. 3).

Only one episode of peritonitis was suspected in one rabbit which developed diarrhea on the fourth day of dialysate instillation. Although its body weight loss was only $100 \mathrm{~g}$, i.e. less than $5 \%$ of total body weight, and fever was not higher than $39.5^{\circ} \mathrm{C}$, the animal was treated with cefuroxime intraperitoneally and gentamicin intramusculary for 7 days. Diarrhea resolved after three days of treatment with the antibiotics.

All rabbits had daily urination and defecation. The only exception was a rabbit with constipation (starting from day 12 after peritoneal catheter placement). This animal received $20 \mathrm{ml}$ of soap water (per rectum) and after this treatment it had daily defecation and a stable body weight.

In one rabbit we noticed subcutaneous dialysate leakage in the abdominal region on the twenty-seventh day of the follow up. The leak was reduced by slowing the rate of dialysate instillation.

\section{Discussion}

Both the uremic state and chronic exposure to PD fluid are associated with a development of functional and structural alterations of the peritoneal membrane
(Stojimirovic et al. 2001, Trpinac et al. 2002). Commercial glucose-based peritoneal dialysis solutions expose peritoneum to hyperosmolar glucose, containing a variable amount of non-enzymatic glucose degradation products. Long-term peritoneal dialysis with glucosebased dialysis solutions has been associated with diabetes-like alterations of peritoneal tissue.

Animal models are important for understanding the physiology and pathophysiology of peritoneal structural and functional alterations during peritoneal dialysis. In vivo studies on animal models permit analysis of dialysis solutions biocompatibility under the conditions that allow interactions between dialysate and peritoneal membrane, as well as dynamic changes in dialysate composition that mimic the clinical situation closely (Zweers et al. 1999, Gaggiotti et al. 2005). Experiments on animal models showed similar morphological alterations of peritoneal membrane as in humans, but after a much shorter time of exposure to bioincompatible dialysis solutions (Topley and Lameire 2001). The toxic effect of bioincompatible dialysis solutions on all peritoneal cell types was proved in in vivo experiments. A large variety of animal models of PD might be a reason why there is still no consensus on the methodology and approach and no ideal model for studying PD.

Rats and rabbits are the most common animal models for PD. Rats are cheap and easy to breed. Certain 
limitations of the rat model are a consequence of rodent physiology. High serum amylase levels in rats are accompanied by high intraperitoneal amylase concentrations. Since amylase causes local degradation of icodextrin followed by a rise in dialysate osmolality, the rat model is inappropriate for evaluation of icodextrin effects (Mortier et al. 2005). Rabbits survive longer than rats on dialysis (Garosi and Di Paolo 2001). The ratio of peritoneal surface area and volume exchange in rabbits and humans is similar (Mortier et al. 2005). The disadvantage of rabbit model, however, is the fact that rabbits are very sensitive animals, difficult to keep.

In order to study PD induced alterations on peritoneal tissue we modified the rabbit model of peritoneal dialysis (Schambye et al. 1992). We have chosen this animal because it was more suitable for housing, feeding and keeping conditions, as well as the possibility of surgical treatment (surgical instruments, improvised peritoneal catheter, biopsies) available to us.

Different methods for fluid instillation during PD on experimental models are used by different authors. In some studies the test fluid was directly injected into the peritoneal cavity. In others, development of custommade miniature peritoneal catheters allowed the so-called «open» PD system, with possible instillation and removal of the PD fluid (Lameire et al. 1998, Pawlaczyk et al. 2001). Another, the so-called «closed» system, uses a permanent catheter tunneled from the peritoneal cavity to the neck of the animal. In this case, drainage of the dialysate is not possible (Margetts et al. 2001, Zareie et al. 2003, Mortier et al. 2004).

Since we did not have an original peritoneal catheter for animals available, we opted for an improvised one. Using a part of the infusion system as a peritoneal catheter proved to be a fairly good option. Animals tolerated it well and it did not cause infection. Dialysate instillations were easily performed, and even dialysate removal was possible, which should enable studies of membrane function in the future. A special advantage of this model is that animals were unrestrained and awake, they had free access to food and water, they tolerated all procedures well and did not lose weight.

The most important technical problems in animal models of chronic PD are frequent obstruction of peritoneal access and development of infection. We would like to stress that during the five-week period of follow up no catheter obstruction occurred among 11 animals in our study. Use of heparin, besides desirable anticoagulant effects, is followed by undesirable effects such as modulation of inflammatory cell activity, proliferation of the cells, synthesis of extracellular matrix and neoangiogenesis (De Vriese et al. 2001). Although we recognize these side effects of heparin, we still prefer to use it rather than to perform omentectomy. As heparin is also used in clinical practice when problems with catheter functioning occur, its usage in animal models actually mimics real-life situations. The use of heparincoated catheters, however, seems to be the method of choice of gaining peritoneal access (De Vriese et al. 2002).

Frequency of dialysate instillation varies among investigators from once to twice or even three times a day. The results suggest that severity of alterations correlates with the number of exchanges, regardless of the overall dialysis time.

Definition of peritonitis in animal models is still arbitrary. Most often used criteria for peritonitis diagnosis are positive dialysate culture and dialysate WBC count higher than 1000 cells $/ \mathrm{mm}^{3}$ (Mortier et al. 2003, 2004). Peritonitis is suspected when there is a more than $5 \%$ daily body weight loss, fever and diarrhea. Different strategies are in use to prevent and treat peritonitis (Zhou et al. 2005). Experimental data support prophylactic administration of antibiotics during the entire study period (Mortier et al. 2003). Prophylactic administration of cefuroxime successfully prevented intraperitoneal infection in animals used for our model of chronic peritoneal dialysate exposure. Only one rabbit showed clinical signs of peritoneal infection, which was successfully cured with an additional antibiotic.

\section{Conclusions}

The presented non-uremic rabbit model of peritoneal dialysis is relatively inexpensive, does not require sophisticated technology and was well tolerated by the animals. Complications such as peritonitis, dialysis fluid leak, constipation or catheter obstruction were negligible. This model is reproducible and can be used to analyze the effects of different dialysis solutions on rabbit peritoneal membrane.

\section{Conflict of Interest}

There is no conflict of interest.

\section{Acknowledgements}

The research was supported by a research grant from the Ministry of Science and Environmental Protection Republic of Serbia No. 145070. 


\section{References}

DE VRIESE AS, MORTIER S, LAMEIRE NH. Non anticoagulant effects of heparin: implications of animal models of peritoneal dialysis. Perit Dial Int 21 (Suppl 3): S354-S356, 2001.

DE VRIESE AS, MORTIER S, CORNELISSEN M, PALMANS E, VANACKER NJ, LEYSSENS A, FAICT D, DE RIDDER L, LAMEIRE NH: The effects of heparin administration in an animal model of chronic peritoneal dialysate exposure. Perit Dial Int 22: 566-572, 2002.

Di PAOLO N, GAROSI G, PETRINI G, MONACI G: Morphological and morphometric changes in mesothelial cells during peritoneal dialysis in the rabbit. Nephron 74: 594-599, 1996.

DOBBIE JW: Peritoneal ultrastructure and changes with continuous ambulatory peritoneal dialysis. Perit Dial Int 13 (Suppl 2): S585-S587, 1993.

GAGGIOTTI E, ARDUINI A, BONOMINI M, VALENTINI G, SACCHI G, SANSONI E, SALVO D, Di PAOLO N: Prevention of peritoneal sclerosis: a new proposal to substitute glucose with carnitine dialysis solution (biocompatibility testing in vitro and in rabbits). Int J Artif Organs 28: 177-187, 2005.

GAROSI G, Di PAOLO N: The rabbit model in evaluating the biocompatibility in peritoneal dialysis. Nephrol Dial Transplant 16: 664-665, 2001.

GOTLOIB L, SHOSHTAK A: Functional structure of the peritoneum as a dialysing membrane. In: The Textbook of Peritoneal Dialysis. R GOKAL, R KHANNA, R KREDIET, KD NOLPH (eds), Kluwer Academic Publishers, Dordecht, 2000.

HAYAT MA: Basic Techniques for Transmission Electron Microscopy. Academic Press, New York, 1986.

LAMEIRE N, VAN BIESEN W, VAN LANDSCHOOT M, WANG T, HEIMBURGER O, BERGSTROM J, LINDHOLM B, HEKKING LP, HAVENITH CE, BEELEN RH: Experimental models in peritoneal dialysis: a European experience. Kidney Int 54: 2194-2206, 1998.

MARGETTS PJ, KOLB M, YU L, HOFF CM, GAULDIE J: A chronic inflammatory infusion model of peritoneal dialysis in rats. Perit Dial Int 21 (Suppl 3): S368-S372, 2001.

MORTIER S, DE VRIESE AS, LEYSSENS A, VANACKER NJ, FAICT D, CORNELISSEN M, DE RIDDER L, LAMEIRE N: Antibiotic administration in an animal model of chronic peritoneal dialysate exposure. Perit Dial Int 23: 331-338, 2003.

MORTIER S, FAICT D, SCHALKWIJK C, LAMEIRE N, DE VRIESE A: Long-term exposure to new peritoneal dialysis solutions: effects on the peritoneal membrane. Kidney Int 66: 1257-1265, 2004.

MORTIER S, LAMEIRE NH, DE VRIESE AS: Animal models in peritoneal dialysis research: a need for consensus. Perit Dial Int 25: 16-24, 2005.

PAWLACZYK K, KUZLAN-PAWLACZYK M, ANDERSTAM B, HEIMBURGER O, BERGSTROM J, WANIEWSKI J, BREBOROWICZ A, LINDHOLM B: Effects of intraperitoneal heparin on peritoneal transport in a chronic animal model of peritoneal dialysis. Nephrol Dial Transplan 16: 669-671, 2001.

SCHAMBYE HT, FLESNER P, PEDERSEN RB, HARDT-MADSEN M, CHEMNITZ J, CHRISTENSEN HK, DETMER A, PEDERSEN FB: Bicarbonate- versus lactate-based CAPD fluids: a biocompatibility study in rabbits. Perit Dial Int 12: 281-286, 1992.

STOJIMIROVIC B, TRPINAC D, OBRADOVIC M, MILUTINOVIC D, OBRADOVIC D, NESIC V: Changes in peritoneal mesothelial cells in patients on peritoneal dialysis. (in Serbian) Med Pregl 54: 219-223, 2001.

STOJIMIROVIC BB, OBRADOVIC MM, TRPINAC DP, MILUTINOVIC DD, OBRADOVIC DI, NESIC VB: Mesothelial paracrystalline inclusions in continuous ambulatory peritoneal dialysis patients. Perit Dial Int 21 (Suppl 3): S54-S57, 2001.

TER WEE PM, BEELEN RH, VAN DEN BORN J: The application of animal models to study the biocompatibility of bicarbonate-buffered peritoneal dialysis solutions. Kidney Int Suppl 88: S75-S83, 2003.

TOPLEY N: Animal models in peritoneal dialysis: more questions than answers? Perit Dial Int 25: 33-34, 2005.

TOPLEY N, LAMEIRE N: Animal models of peritoneal dialysis, Discussion. Nephrol Dial Transplant 16: 683-685, 2001. 
TRPINAC DP, STOJIMIROVIC BB, OBRADOVIC MM, MILUTINOVIC DD, OBRADOVIC DI, NESIC VB: Effect of uremia and peritoneal dialysis on peritoneal mesothelial cells. (in Serbian) Vojnosanit Pregl 59: 17-21, 2002.

WILLIAMS JD, CRAIG KJ, TOPLEY N, VON RUHLAND C, FALLON M, NEWMAN GR, MACKENZIE RK, WILLIAMS GT; PERITONEAL BIOPSY STUDY GROUP: Morphologic changes in the peritoneal membrane of patients with renal disease. J Am Soc Nephrol 13: 470-479, 2002.

ZAREIE M, HEKKING LH, WELTEN AG, DRIESPRONG BA, SCHADEE-EESTERMANS IL, FAICT D, LEYSSENS A, SCHALKWIJK CG, BEELEN RH, TER WEE PM, VAN DEN BORN J: Contribution of lactate buffer, glucose and glucose degradation products to peritoneal injury in vivo. Nephrol Dial Transplant 18 : 2629-2637, 2003.

ZHOU JY, XU PF, CHEN H, YU YS, CHEN YG: Therapeutic effect of ceftazidime in rabbit model of peritonitis caused by Escherichia coli producing CTX-M-14 extended-spectrum beta-lactamase. Zhonghua Jie He He Hu Xi Za Zhi 28: 689-693, 2005.

ZWEERS MM, DOUMA CE, DE WAART DR, VAN DER WARDT AB, HO-DAC-PANEKEET MM, KREDIET RT, STRUIJK DG: The standard peritoneal permeability analysis in the rabbit: a longitudinal model for peritoneal dialysis. Perit Dial Int 19: 56-64, 1999. 